\title{
The Analysis of Stress Causes in the Education of Professionals in the Romanian Academic Environment Compared to Other European Countries
}

\author{
Mona Vintila, ${ }^{1}$ Sorin D. Vintila ${ }^{2}$ \\ ${ }^{1}$ Faculty of Psychology, West University of Timisoara, Romania, mona.vintila@e-uvt.ro \\ ${ }^{2}$ Tibiscus University of Timisoara, Romania, daniel_sorin_9@ yahoo.com
}

\begin{abstract}
In the frame of our project titled "WELNESS-Skills for true wellbeing," we had the possibility to assess the main factors which adult educators identify as stress causes in the Romanian higher education system. Through this project, we identified tools which would enable educators to reduce their stress level and to enhance their level of wellbeing. All participants acknowledged the usefulness of the training in relation to understanding how one's perceptions influence one's communication. Participants from Romania fully agreed on the usefulness of the training course in relation to the knowledge and practical tools for active listening, non-verbal communication and giving feedback.
\end{abstract}

\section{Keywords}

Adult education; educators; communication and relationships; active listening; feedback.

The project has been funded with support from the European Commission. This report reflects the views only of the author, and the Commission cannot be held responsible for any use which may be made of the information contained therein. "Skills for True Wellbeing" - Wellness 527797-LLP-1-2012-1-RO-GRUNDTVIG-GMP

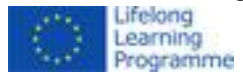

This is an Open Access article distributed in accordance with the Creative Commons Attribution Non Commercial (CC-BYNC-ND 4.0) license, which permits others to copy or share the article, provided original work is properly cited and that this is not done for commercial purposes. Users may not remix, transform, or build upon the material and may not distribute the modified material (http://creativecommons.org/licenses/by-nc/4.0/)

DOI: 10.22618/TP.PCMS.20164.349010 


\section{Introduction}

\section{A. Background: The Implementation of Wellbeing Pilot Courses for Educators/ Professionals/} Tutors

In an attempt to identify and develop self-management skills to create satisfying levels of sustainable Wellbeing, the consortium of the European partnership project (Skills for True Wellbeing, 527797LLP-1-2012-1-RO-GRUNDTVIG), engaged in a Transnational Wellbeing Analysis to examine a baseline Wellbeing level in Educators/Professionals/Tutors on National and European levels as well as define key needs related to promoting Wellbeing. Assessing stress sources in each participating organization both for adult educators and adult learners was a main task for our project. The next step was the identifying efficient ways to reduce stress in the process of adult education.

\section{B. Conceptual Framework: The Implementation of Wellbeing Pilot Courses for Educators/} Professionals/Tutors

Educators Subjective Wellbeing (SWB) is usually conceptualized in terms of people's emotional responses (good or bad feelings) and their cognitive or evaluative responses e.g. 'satisfaction.' However, as noted in our (Skills for True Wellbeing, 527797-LLP-1-2012-1-RO-GRUNDTVIG) project, this conceptualization regards Wellbeing as a state rather than a process (Rogers, 1961). It focuses on having positive feelings or evaluations, as opposed to doing certain things that lead to lasting pleasure or fulfillment. ${ }^{2}$ This distinction was fundamental to the development of our partnership project. It parallels two distinct philosophical approaches to Wellbeing - the hedonic approach which emphasizes positive feelings ${ }^{3}$ versus the eudaimonic approach which emphasizes positive functioning. ${ }^{4}$

\section{Methodological Framework: The Implementation of Wellbeing Pilot Courses for Educators/Professionals/Tutors}

The following are courses that were available to all participants from seven participating institutions and six countries:

- Stress and Health;

- Communication and Relationships; and,

- Effective Teaching Methods.

Each organisation chose two out of three courses most relevant after their local assessment. In this paper we will refer just to the results of implementing the course on Communication and

\footnotetext{
${ }^{1}$ R. Veenhoven, "The four qualities of life. Ordering concepts and measures of the good life", Journal of Happiness Studies, 1 (2000): 1-39.

2 J. Vitterso, "Subjective well-being versus self-actualization: Using the flow-simplex to promote a conceptual clarification of subjective quality of life", Social Indicators Research, 65 (2004): 299-331.

${ }^{3}$ Daniel Kahneman, Ed Diener and Norbert Schwartz, ed. Well-Being: The Foundations of Hedonic Psychology. (New York: Russell Sage Foundation, 1999).

${ }^{4}$ Keyes, Corey L. M. "Promoting a Life Worth Living: Human Development from the Vantage Points of Mental Illness and Mental Health," in Promoting Positive Child, Adolescent, and Family Development: A Handbook of Program and Policy Innovations, Volume 4, ed. Richard M. Lerner, Francine Jacobs, and Donald Wertlieb (Thousand Oaks, CA: Sage, 2003), 257-274.
} 
Relationships. The partner institutions from five countries that chose to implement the Communication and Relationships Courses (a 2 day course) for Educators/Professionals/Tutors were: UK, Slovenia, Romania, Italy (Promimpresa) and Cyprus.

\section{Methodological Framework: Research Tools for Educators/Professionals/Tutors: Wellbeing Pilot Courses}

Implementation of the Educators Wellbeing Courses was a pilot with three phases.

Phases 1 and 2: Pre and Post- questionnaire: All partners used the same questionnaires for the implementation of all the courses. The sample was selected from all participants for the courses: a representative population of Educators/ Professionals/Tutors aged over 25 were selected by each of the country teams.

Phase 3: Semi-Structured Interviewing: One month after the training each partner conducted semistructured interviewing with participants in order to examine the impact of the course. The semistructured interviews focused on contexts, mechanisms and impact to examine what is happening in each country. In addition, the semi-structured interviews focused on Wellbeing interventions, Wellbeing measures and change(s) were recorded by all the partners. Each of the data compares the Pre-questionnaire of how "people felt" at the beginning of the course while the Post-questionnaire relate to the "course specific part". The responses were on a scale of " 0 to 10 " with 0 being very low and 10 being extremely high. A pre-test, post-test design was used to detect changes.

\section{A. Phase 1 and 2: Pre and Post-questionnaires}

The average responses were that all participants from the UK, Romania and Cyprus rated their communication skills as high (mean scores: 7.9, 8.6, 7.1). However, Italy/Formazione and Slovenia reported lower scores in comparison (mean scores 6.3 and 6.0,). Romanian participants reported the highest score (mean score: 8.6).

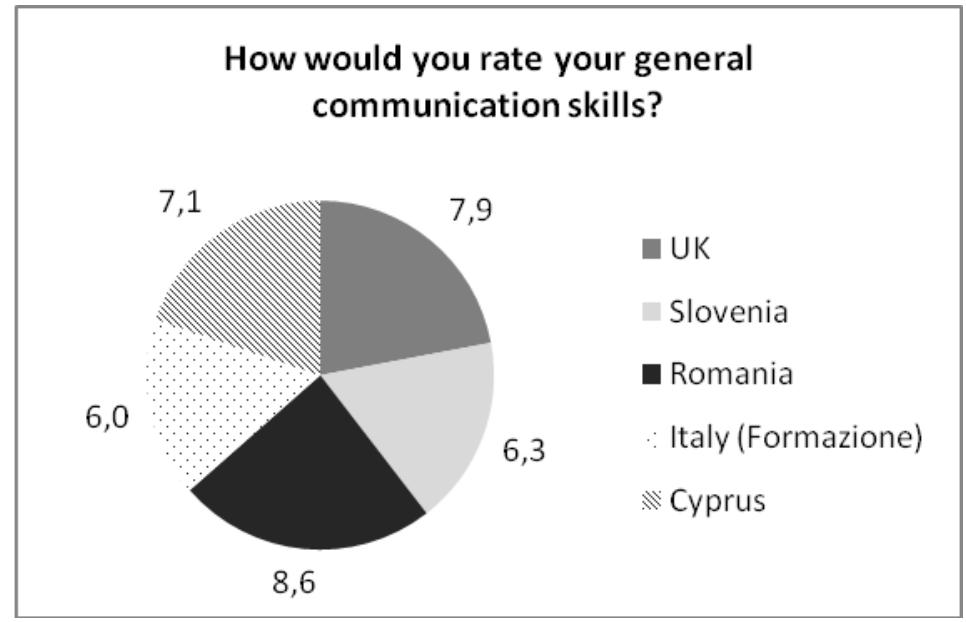

Fig.1. General communication skills

Participants were asked to rate their own understanding of the influence of perceptions on communication processes. In response to this question, participants from Romania, UK and Cyprus reported higher levels of perceptual influences on communication processes (mean score 9.2, 7.6, 
7.7,), while Italy/Formazione and Slovenia reported similar ratings of responses as follows: (mean scores $6.3,6.9$ ). Romanian participants reported the highest score, 9.2, higher than those reported by the other participants.

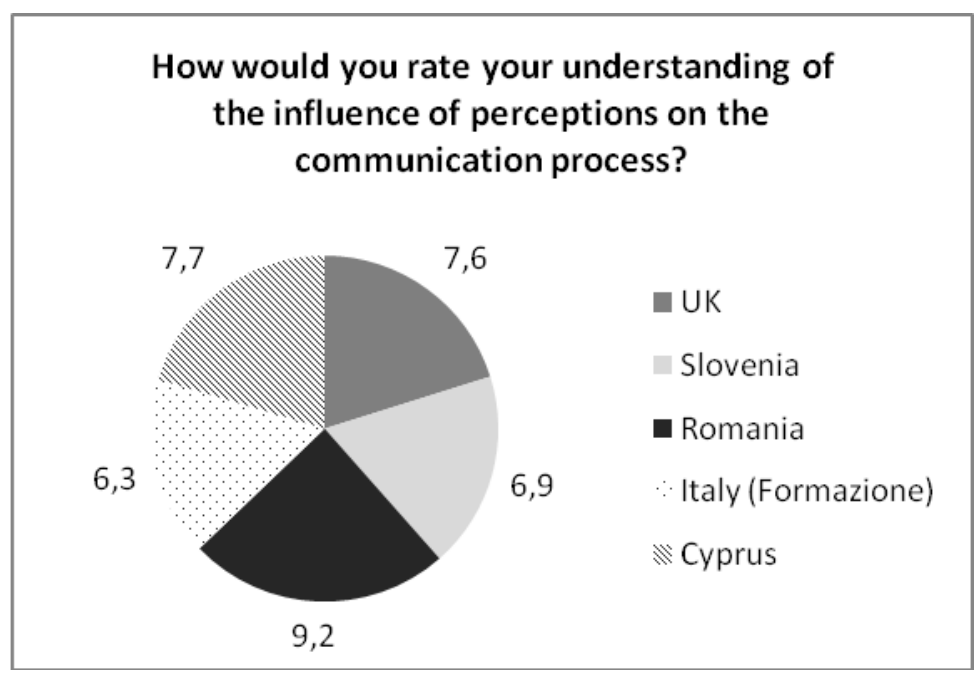

Fig. 2. The understanding of the influence of perceptions on communication processes

When asked to rate their awareness of non-verbal cues in communication skills Romania, UK, Cyprus and Slovenia participants reported the highest level of self awareness of non verbal cues in communication. Participants from Italy/Formazione reported the lowest mean score (6.3), while those from Romania reported the highest mean score (8.0).

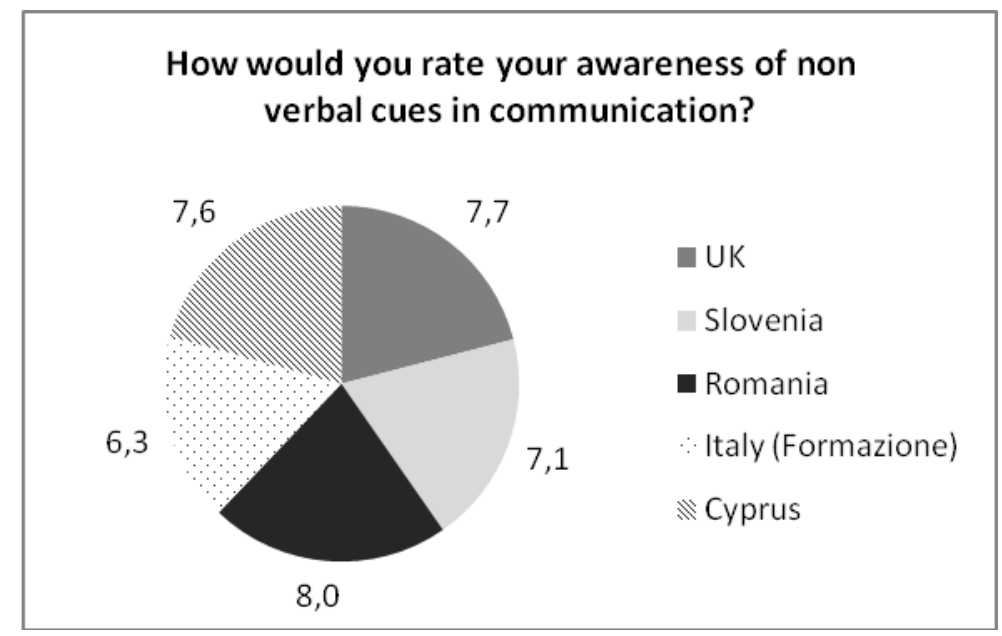

Fig. 3. The awareness of non-verbal cues in communication skills

Similarly, the rating of an ability to give and receive feedback in a constructive way was rated highly by participants from Romania (mean score: 8.2) and the UK (mean score: 7.9). Participants from Slovenia, Italy/Formazione and Cyprus reported mean scores closely related to each other (mean scores $6.8,6.5,6.4)$. We observe the lower average scores at these answers demonstrates that giving and receiving feedback in a constructive way is perceived as a different task. 


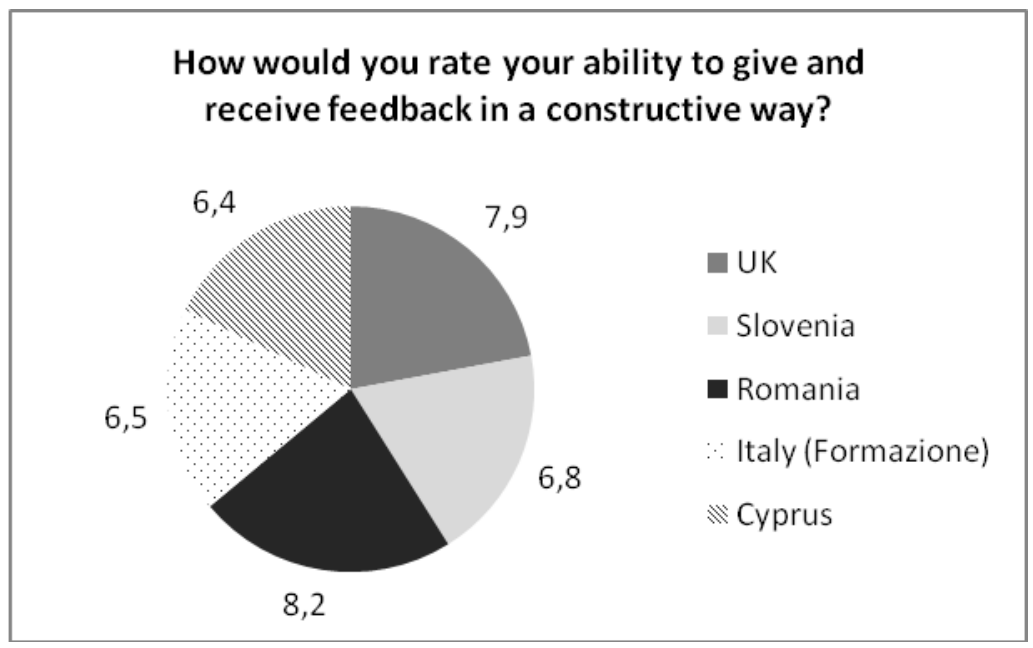

Fig. 4. The ability to give and receive feedback in a constructive way

The ratings that relates to an understanding of what makes public speaking effective, participants from Romania reported the highest mean score (7.8), followed by the UK (7.6), then Cyprus (7.1) with the remaining of the countries recording similar ratings: Slovenia and Italy/Formazione (mean scores: $6.3,6.3$ ). In this case we observe lower average scores and even the Romanian participants reported lower scores (7.8), indicating that public speaking is a sensitive topic for many professionals involved in adult education, despite the fact that it is a task to be fulfilled on a daily bases.

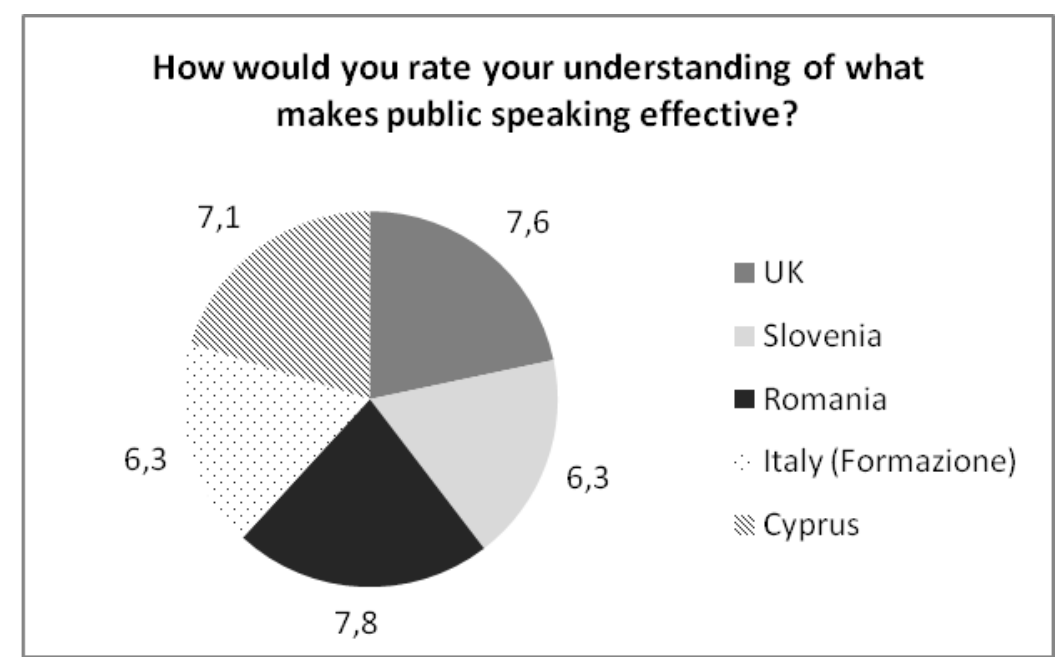

Fig. 5. The understanding of what makes public speaking effective

The Post-questionnaire (day 1) for all five institutions from five countries (UK, Romania, Cyprus, Italy /Formazione and Slovenia) indicates that all participants highly acknowledged the usefulness of the training in relation to the understanding about how one's perceptions influence one's communication, as represented by the following ratings: Cyprus (mean score 9.7), closely followed by Romania (mean score 9.2), UK (mean score 8.9), Italy/Formazione (mean score 8.5), and Slovenia (mean score 8.4). 


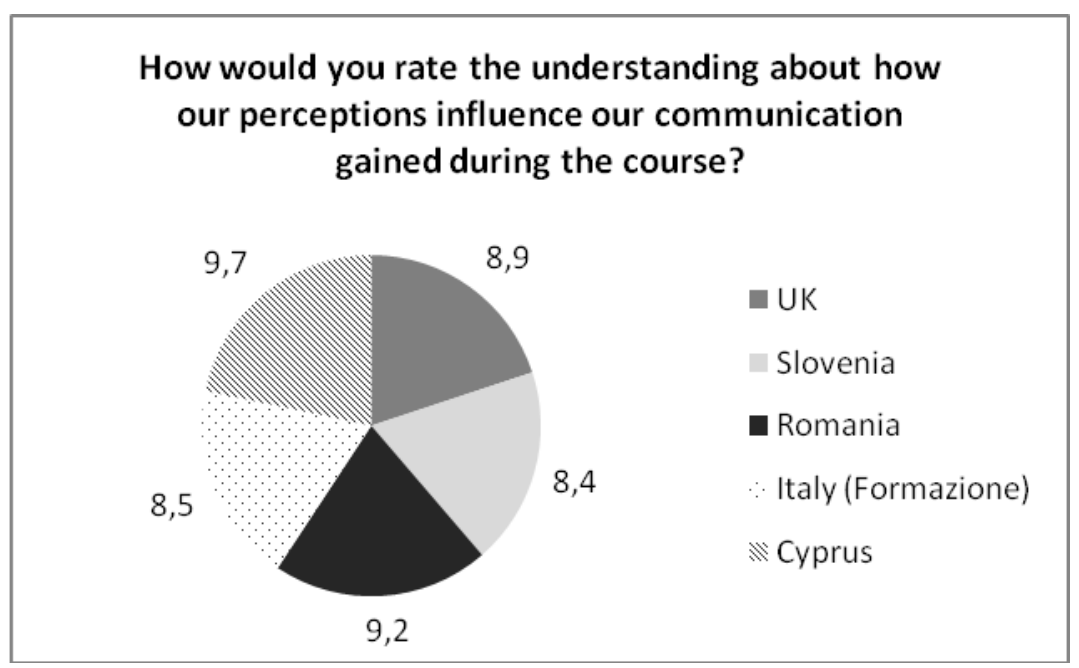

Fig. 6. The understanding about how one's perceptions influence one's communication

Participants from two countries highly acknowledged the training regarding the topic of nonverbal cues in communication after training with the following ratings (Romania, mean score: 9.4 and 9.3 for Cyprus). We observe the increase of the scores from day one for all participants; the Italian participants who scored 6.3 now reported 8.8, while the Romanian participants reported 9.4 compared to 8.0 on the first day. This demonstrates the positive impact of the course.

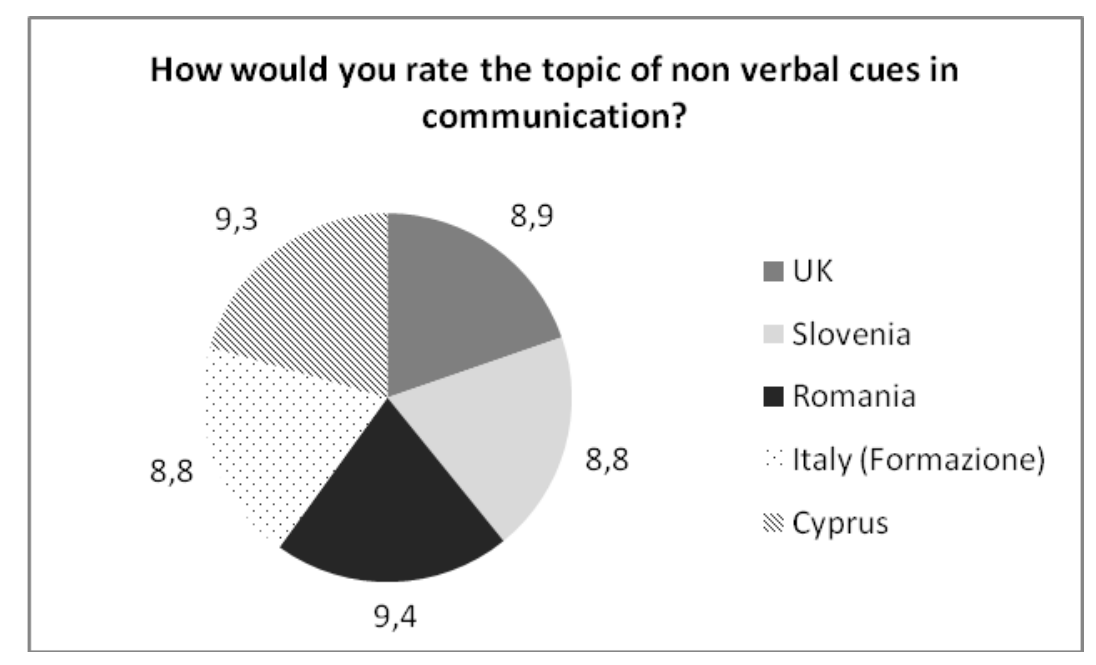

Fig. 7. The topic of non verbal cues in communication after training

Participants from Romania agreed 100 percent on the usefulness of the training course in relation to the knowledge and practical tools for giving feedback introduced during the training; their scores were closely followed by Cyprus (mean score 9.9). UK participants (mean score 8.3), Italy/Formazione (mean score 8.3) and Slovenia (mean score 8.0). All participants acknowledged that the tools for feedback were highly favorable. We observed the importance given by the Romanian participants to the topic of feedback in the process of adult education; this is seen as a main ingredient in an effective teaching process. 


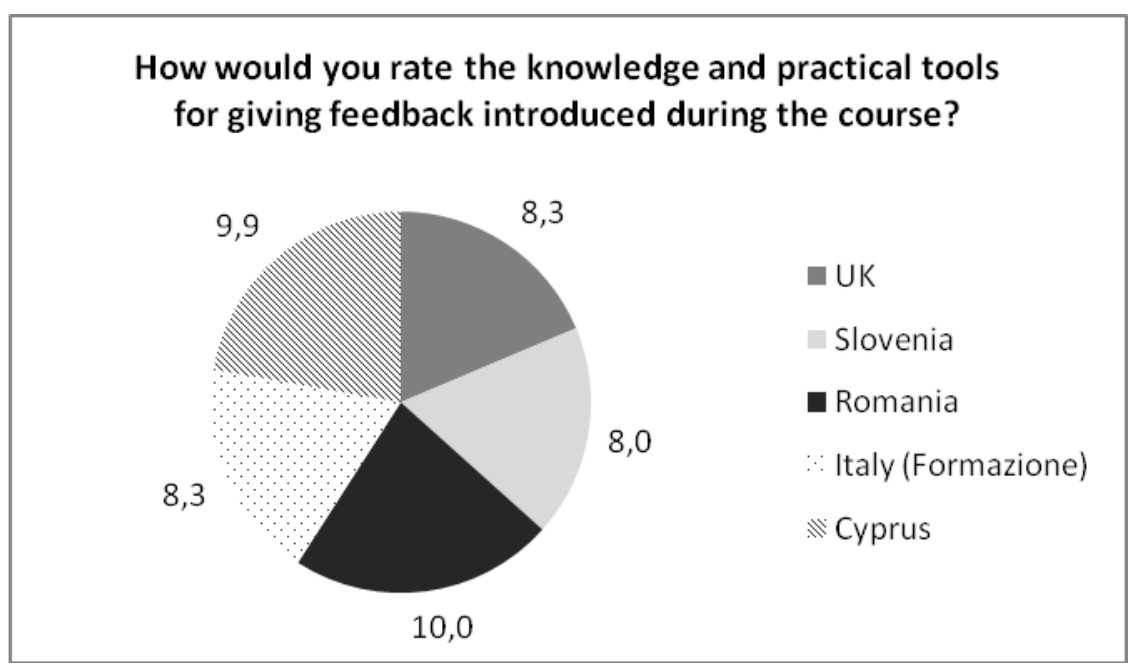

Fig. 8. The knowledge and practical tools for giving feedback

All the participants believed their ability to give and receive feedback had increased effectively after attending the training with the respective ratings: UK (8.8), Slovenia (8.2), Romania (8.8), Italy /Formazione (7.8), and Cyprus (9.0).

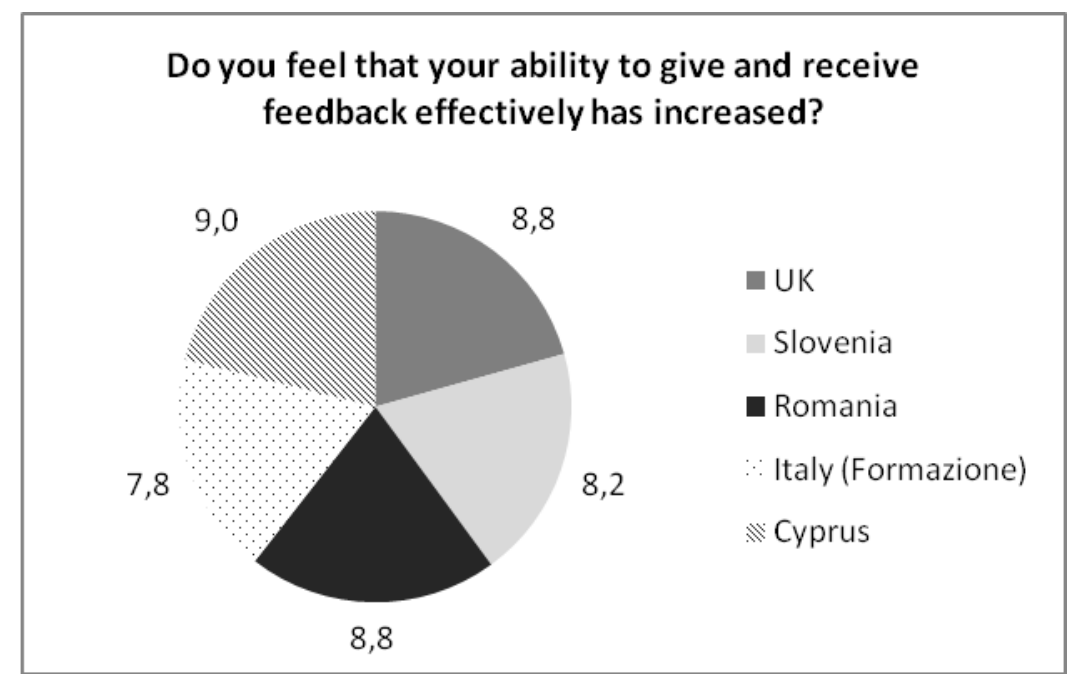

Fig. 9. The ability to give and receive feedback

Before day 2 of the training on Communication and Relationships, all participants were asked to rate their public speaking skills. The highest scores were reported by UK participants (mean score 8.5), closely followed by Romania (mean score 8.2) and Italy/Formazione (mean score: 7.3). Slovenia (mean score 5.3) and Cyprus (mean score 5.7) had similar scores. We observe a difference between the understanding of the significance of public speaking and the skills to do it: participants from Cyprus had higher understanding (7.1) but still reported to have lower skills (5.7) while participants from Italy reported lower scores at understanding (6.3) but higher scores on skills (7.3). 


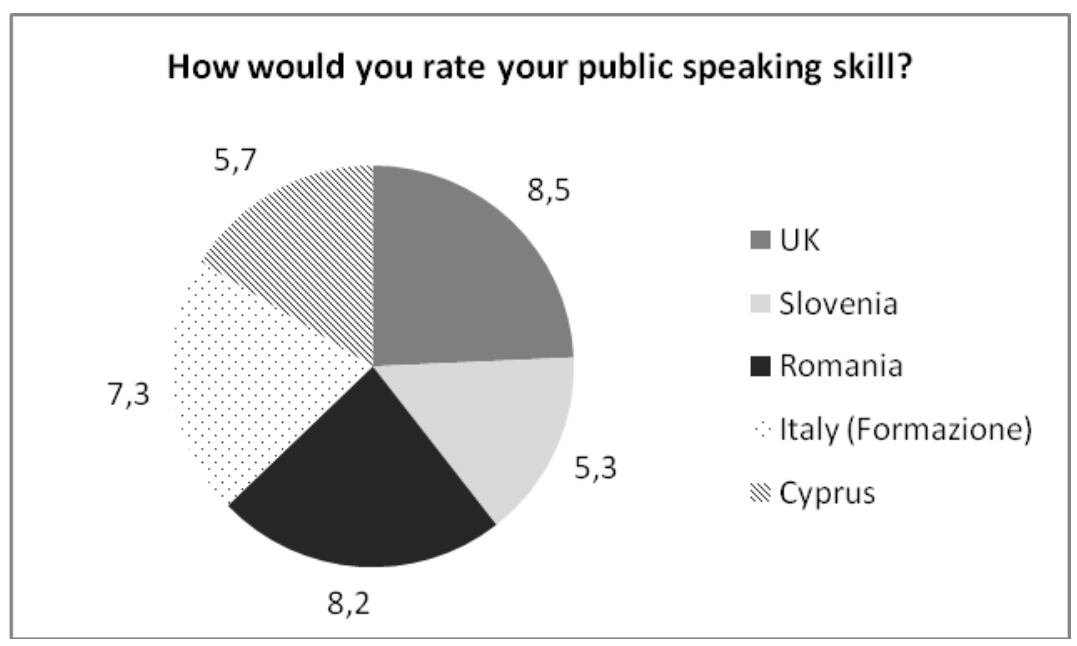

Fig. 10. The public speaking skill

The UK participants also reported the strongest sense of listening skills (mean score 9.0), closely followed by Romania (mean score 8.6), Slovenia (mean score 7.2), and Cyprus (mean score 7.4). However, Italy/Formazione reported the lowest mean score (5.8). We observe here the highest ability to listen reported by UK participants, followed by the Romanians, while Italian participants, despite their job as adult educators, probably through cultural influences, reported a lower ability to listen (5.8).

\section{How would you rate your listening skill?}

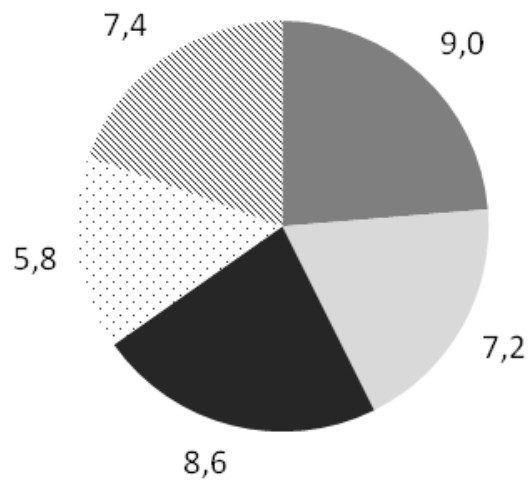

UK

Slovenia

Romania

Italy (Formazione)

NCyprus

Fig. 11. The listening skills

When rating an understanding of what it takes to build satisfying relationships, UK participants reported a higher understanding of this (mean score 8.9), followed by Romania (mean score 8.2) and Cyprus (mean score 7.4) with the lowest score reported by Italy/Formazione (mean score 5.8). 


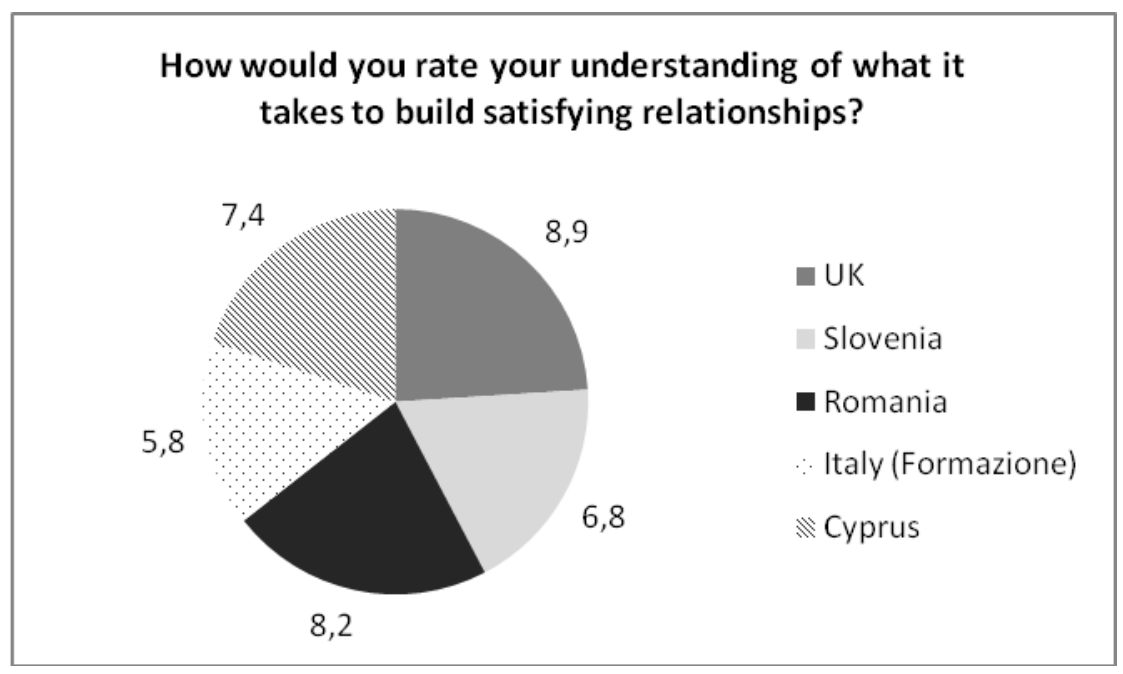

Fig. 12. The understanding of what it takes to build satisfying relationships

When participants were asked to rate their ability to build and maintain satisfying relationships, the UK participants rated their ability highly (mean score 8.7 ), followed by participants from Romania (mean score 8.2), Italy/Formazione (mean score 7.2), and Slovenia (mean score 7.0). Cyprus reported the lowest score, although it was still above the average (mean score 6.7). We observed that while participants from Cyprus scored higher on understanding the phenomenon, they reported lower scores on implementing it, while the Italian participants, despite lower understanding scores, reported higher scores on implementation.

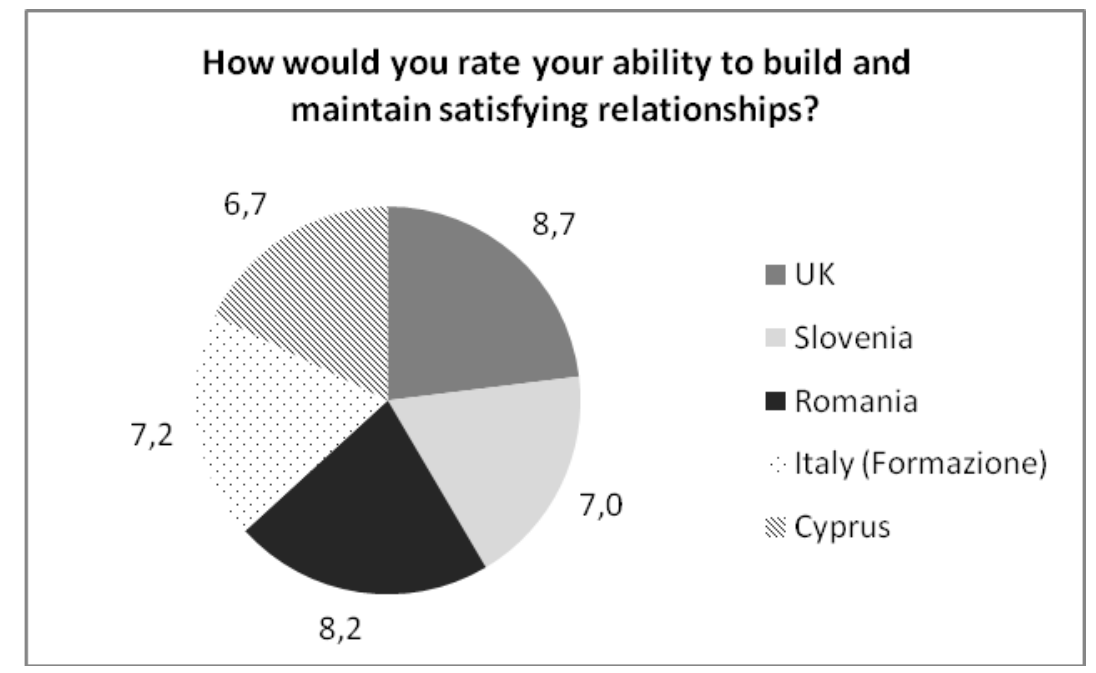

Fig. 13. The ability to build and maintain satisfying relationships

Finally, the participants were asked to rate their ability to communicate in an assertive way before the training. The UK participants rated their abilities the highest (mean score 8.7) closely followed by Romania (mean score 8.4). However, Italy/Formazione reported the lowest below average score (mean score 4.5) with Cyprus reporting above average (mean score 5.4). 


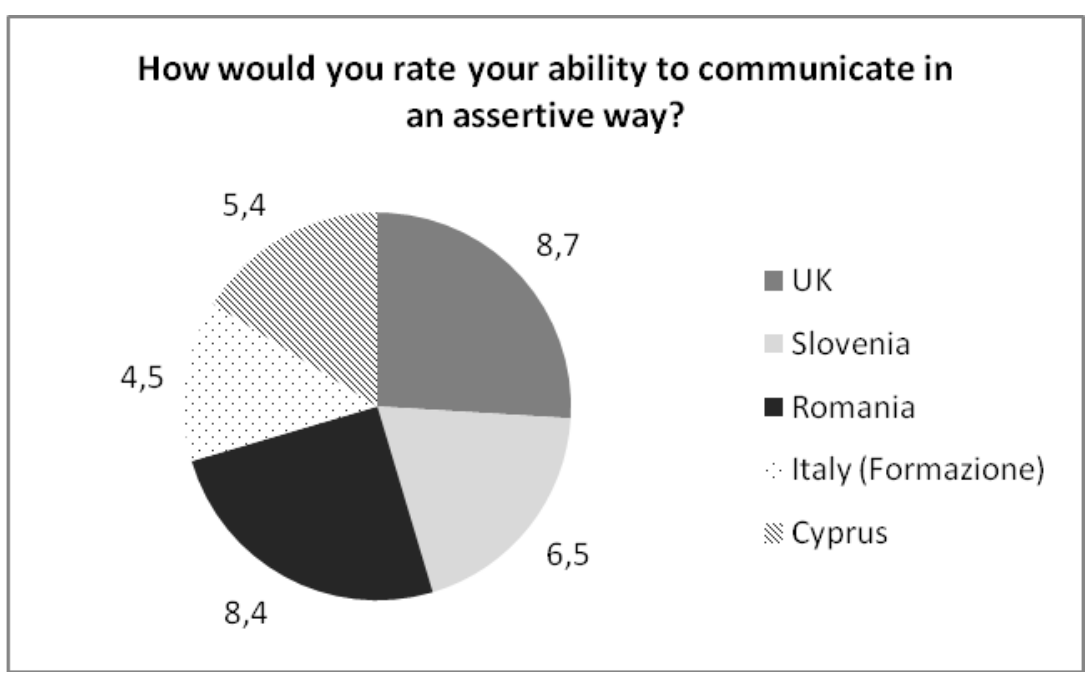

Fig. 14. The ability to communicate in an assertive way

After training on Communication and Relationships, on day 2 all the participants agreed about the usefulness of the practical exercises regarding the public speaking model. Average scores were as follows: UK (mean score 8.1), Slovenia (mean score 7.4), Romania (mean score 8.8), Italy/Formazione (mean score 8.5), and Cyprus (mean score of 8.3).

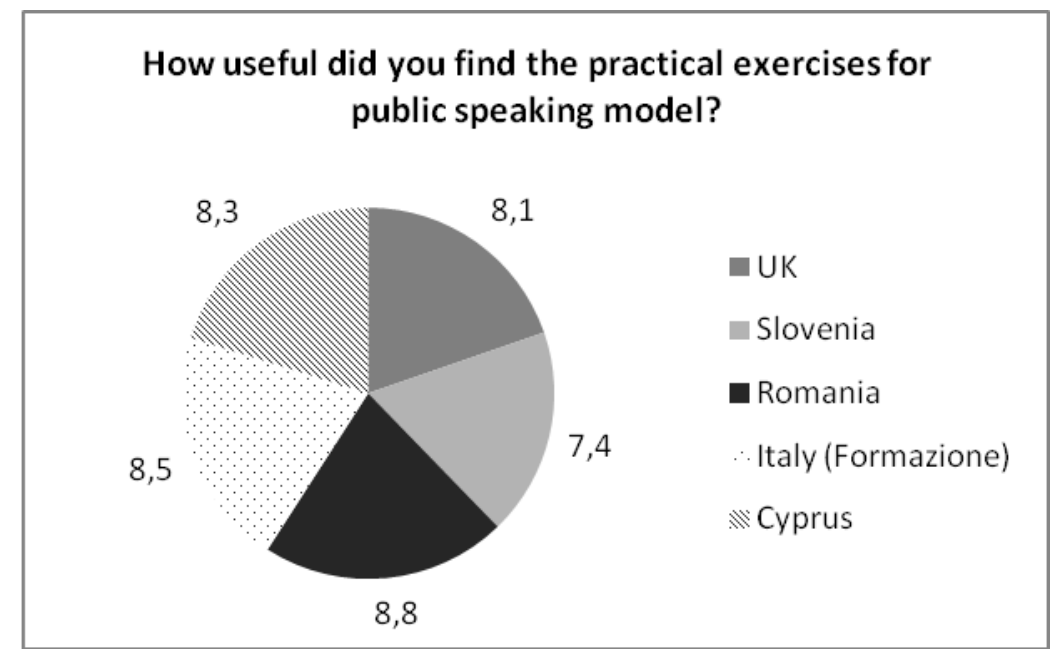

Fig. 15. The usefulness of the practical exercises regarding the public speaking model

After the training, all of the participants reported that the topic of active listening in terms of concentrating on what is being said rather than just passively 'hearing' the message of the speaker was very useful. The following are the mean mean scores: UK (8.4), Slovenia (7.5), Romania (9.4), Italy/Formazione (8.7), and Cyprus (9.1). We observe the highest scores related to the importance of active listening were reported by the Romanian participants. We also observe an increase in scores for the participants from Cyprus who scored 7.4 at this topic before and those from Italy who had an average of 5.8 before and now scored above the average. 


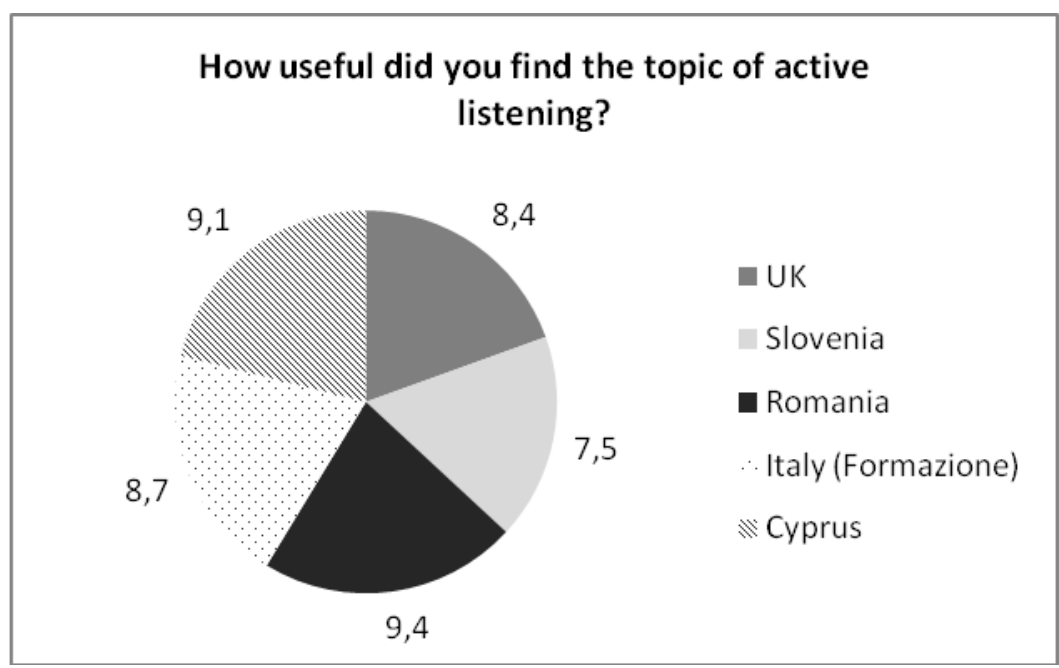

Fig. 16. The topic of active listening

In terms of the training on discussions about relationships, all participants reported high mean scores about the usefulness of the training. Participants from Cyprus reported the highest mean score (9.4), closely followed by Romania (mean score 9.2), and UK, (mean score 8.9) while Slovenia (mean score 8.6) and Italy/Formazione (mean score 8.5 ) were close in their average scores.

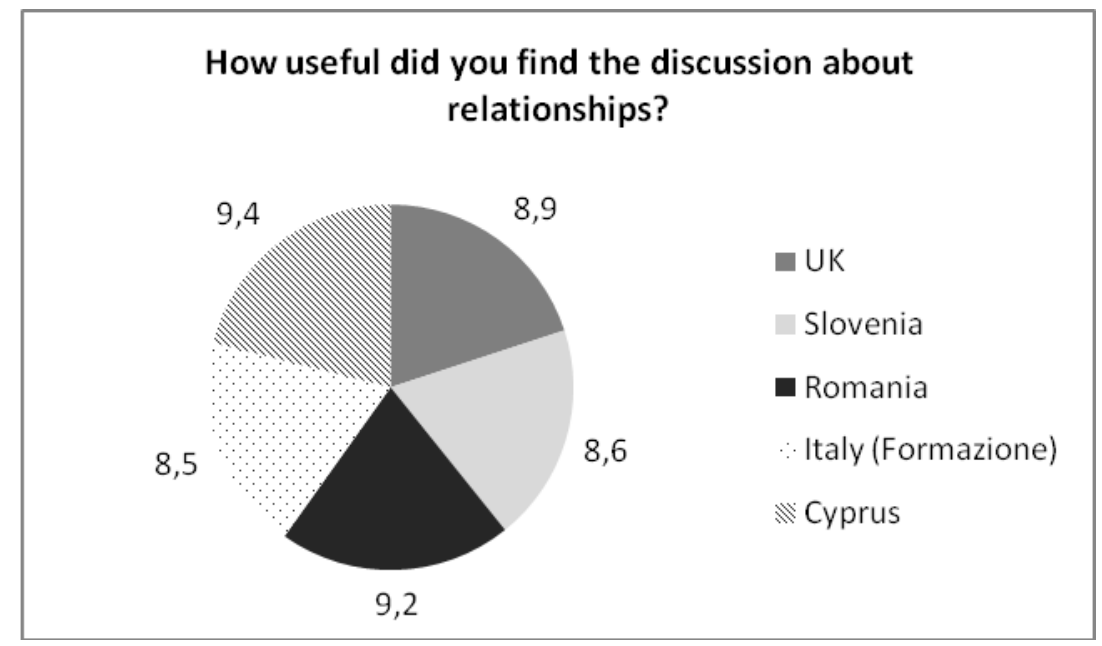

Fig. 17. The usefulness of the dicussion about relationships

All participants rated the training on the usefulness of the knowledge and techniques for assertive communication skills. 


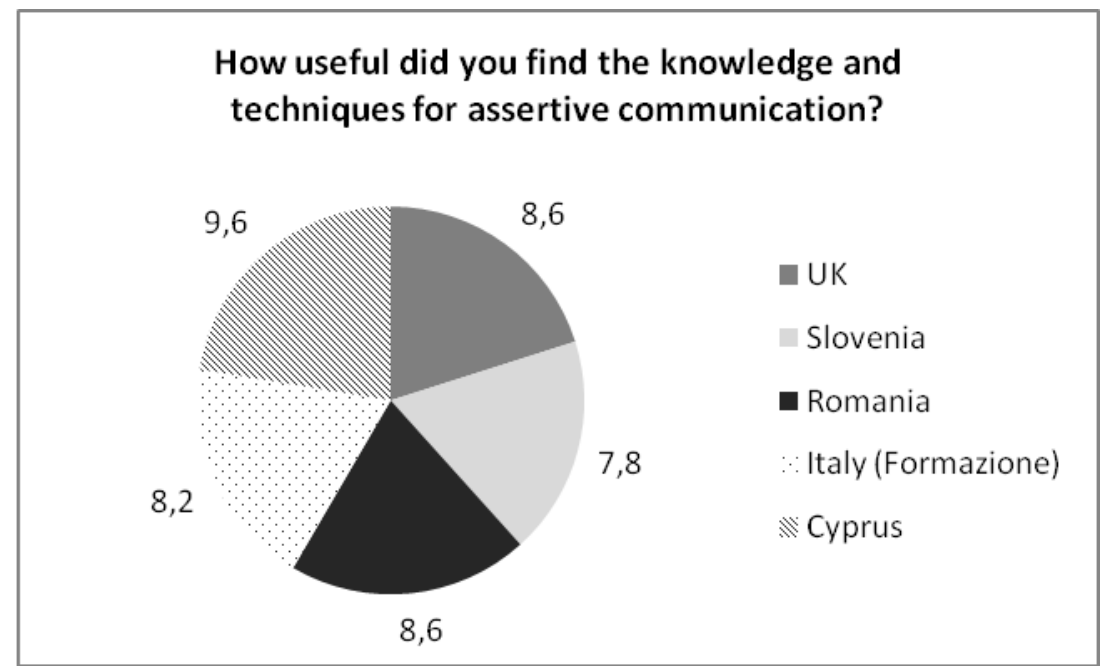

Fig. 18. The knowledge and techniques for assertive communication skills

The concept of skills/knowledge that related to the training on building more satisfying relationships were highly rated by all participants as follows: UK (mean score 8.8 ), Slovenia (mean score 8.0), Romania (mean score 9.0 ), Italy /Formazione (mean score 8.5), and Cyprus (mean score $9.4)$.

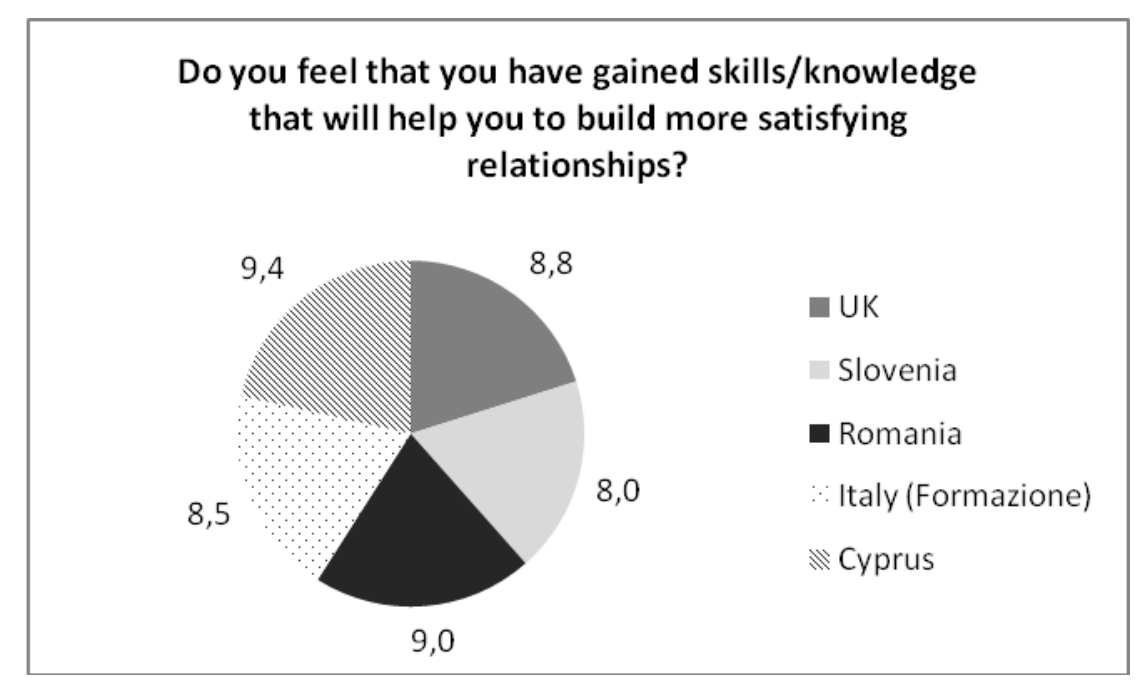

Fig. 19. Skills/knowledge that related to the training

Overall all of the participants from all of the countries reported high scores for the training program regarding gaining skills to improve one's assertiveness with the following mean scores: UK (8.9), Slovenia (7.7), Romania (8.2), Italy/Formazione ( 8.3), and Cyprus (mean score 9.4 ). We observe here that Romanian participants had the second lowest results, 8.2, meaning that maybe they gained less new information than other participants regarding assertiveness. 


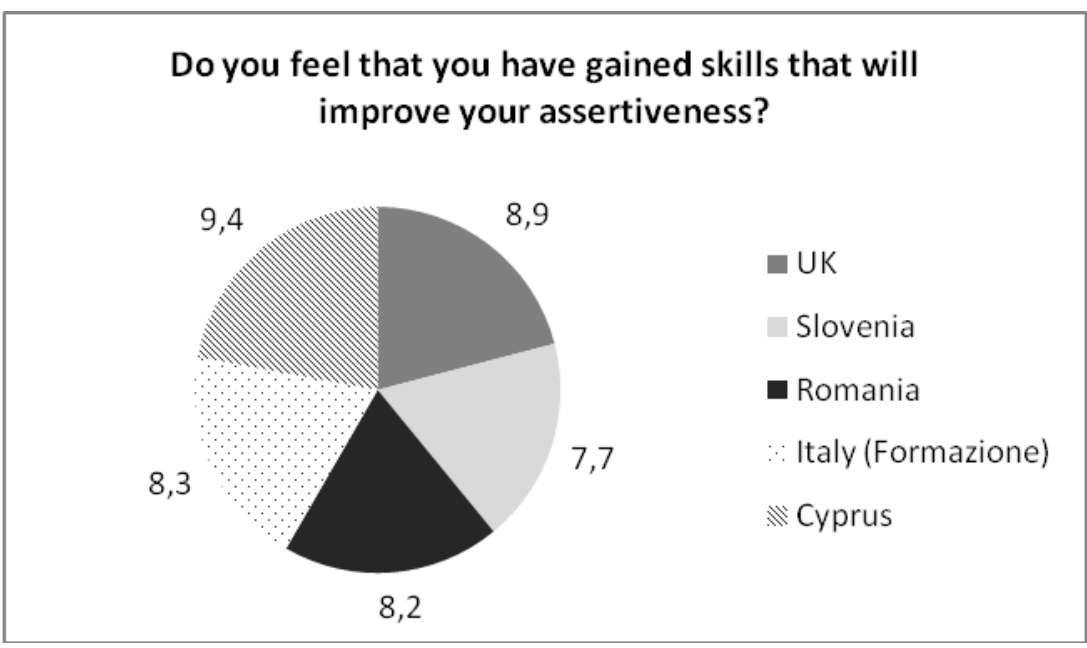

Fig. 20. Skills to improve one's assertiveness

In addition, all participants strongly believed they would be able to enhance their public speaking skill after the training as demonstrated by these averages: UK (8.7), Slovenia (7.7), Romania (mean score 8.6), Italy /Formazione (mean score 8.5), and Cyprus (mean score 8.3).

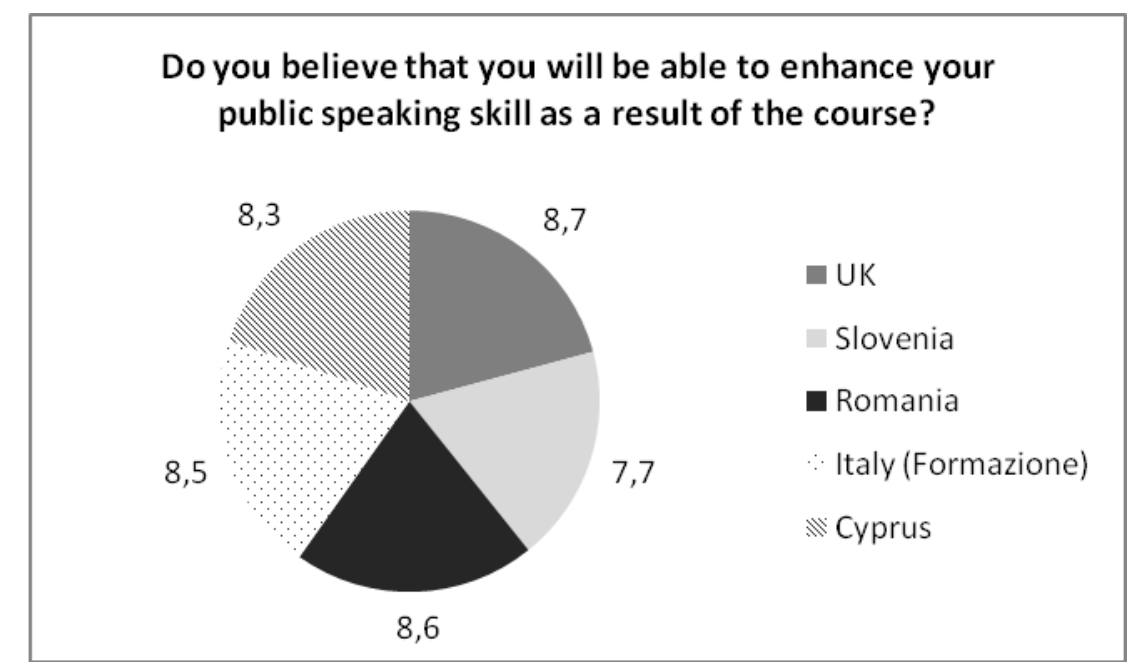

Fig. 21. Public speaking skill after the training

All participants rated the ability to accurately receive and interpret information in the communication process as favorable. Participants indicated that they are better listeners as a result of the training. 


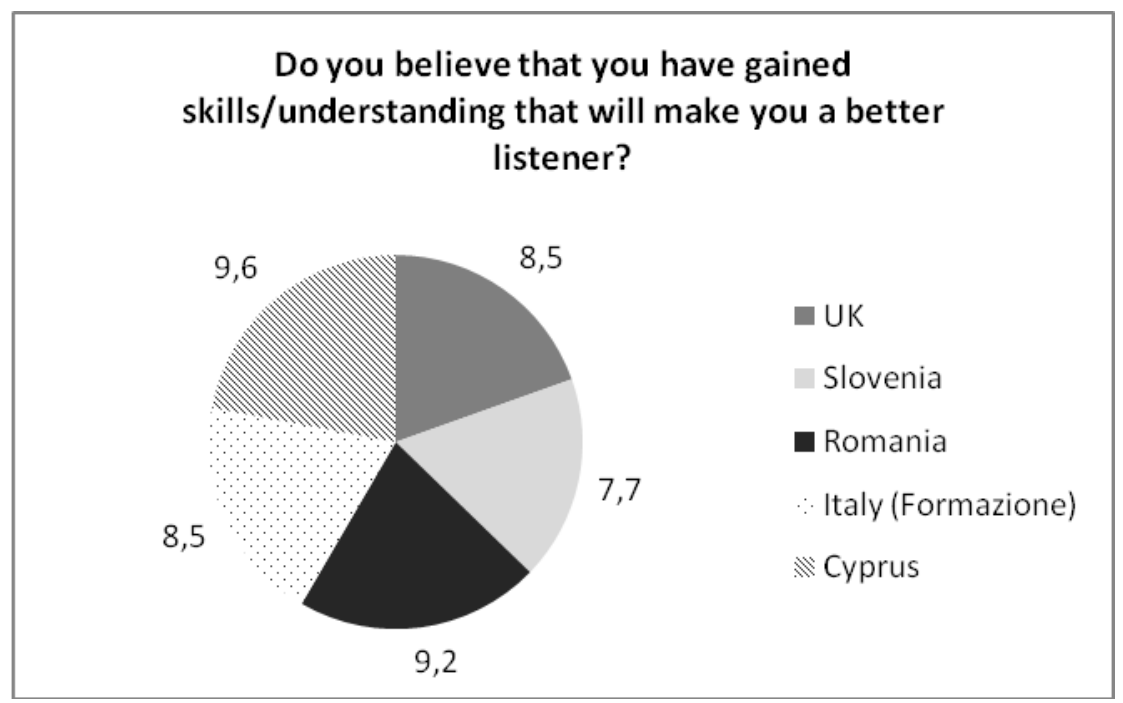

Fig. 22. Skills/understanding for a better listening

\section{B. Phase 3: Semi-Structured Interviewing}

The third phase of the implementation of all the pilot courses for Communication and Relationships focused on semi-structured interview data collected for five or more Educators/Professionals/Tutors about a month after training was completed. Participants were asked to give an account of how the training had enhanced their ability to explore and improve their understanding of different communication processes. In addition they were asked how the knowledge and practical tools, presented in the course, enhanced their personal and professional relationships. The questions were carefully chosen to stimulate discussions on matters of wellbeing and to allow participants to identify issues they deemed significant.

\section{Conclusion}

The course helped participants apply active listening skills in their personal and professional life with improved awareness of non-verbal communication skills.

Most of the participants also talked about the significance of giving feedback, active listening, and non-verbal clues (body language). Additionally, participants reported that they have become more aware of the tone of communication and how others may perceive it. They have become more aware of the fear of facing certain communication processes and have become more confident in overcoming them. The ability to communicate information accurately, clearly and as intended, has provided vital skills and improved their quality of life. Similarities also emerged in people's experiences and awareness of difficult situations and using calmness, respect and assertiveness to resolve them. Positive lessons can be drawn from all countries from the perspective of increasing the application of new skills in communication to handle conflicts, communicate more effectively, and manage stress assertively.

In the future we should consider also the professional background of the teachers; for those professionals in adult education who have a psychological background it was easier to fulfill the training tasks but maybe not as stimulating or challenging as for those coming from a completely different background. 
Another aspect worth mentioning is that the training can bring important skills not only in the professional domain but also in the personal life of the participants. Active listening, giving feedback, and understanding non-verbal cues are skills that can be extremely useful in improving personal relationships, too.

The practical tools helped people to better structure their stress management practices and their communication processes.

In addition, all approaches must take a holistic view to promoting health and wellbeing, one that takes account of the stages of growth, development and maturity of each individual and the social, community and educational context in which they live and work.

\section{References}

Kahneman, Daniel, Diener, Ed and Schwartz, Norbert, ed. Well-Being: The Foundations of Hedonic Psychology. New York: Russell Sage Foundation, 1999.

Keyes, Corey L. M. "Promoting a Life Worth Living: Human Development from the Vantage Points of Mental Illness and Mental Health," Pp. 257-274 in Promoting Positive Child, Adolescent, and Family Development: A Handbook of Program and Policy Innovations, Volume 4, edited by Richard M. Lerner, Francine Jacobs, and Donald Wertlieb, Thousand Oaks, CA: Sage, 2003;

Veenhoven, R. "The four qualities of life. Ordering concepts and measures of the good life", Journal of Happiness Studies, 1 (2000): 1-39.;

Vitterso, J. "Subjective well-being versus self-actualization: Using the flow-simplex to promote a conceptual clarification of subjective quality of life", Social Indicators Research, 65 (2004): 299331. 